\title{
FATORES DE DESEMPENHO E CONSUMO DE ENTRETENIMENTO DE VIDEOS EM STREAMING
}

\section{PERFORMACE FACTORS AND ENTERTAINEMENT VIDEO STREAMING CONSUMPTION}

\author{
Andressa Rodrigues Silva \\ Bacharel em Administração pela Universidade Federal de Minas Gerais - UFMG. \\ Belo Horizonte, MG, Brasil \\ E-mail: andressarsilva@hotmail.com \\ Marlusa de Sevilha Gosling \\ Docente Associada do Departamento de Ciências Adminnistrativas da Universidade Federal de Minas Gerais - UFMG. \\ Belo Horizonte, MG, Brasil \\ E-mail: mg.ufmg@gmail.com \\ Kelly Cristine Oliveira Meira \\ Bacharel em Relações Econômicas Internacionais pela Universidade Federal de Minas Gerais - UFMG. \\ Bolsista do Neecim-Tur UFMG \\ Belo Horizonte, MG, Brasil \\ E-mail: kellycristineomeira@gmail.com \\ Stela Cristina Hott Correa \\ Doutoranda em Administração pela Universidade Federal de Minas Gerais - UFMG. \\ Docente da Universidade Federal de Juiz de Fora -UFJF \\ Belo Horizonte, MG, Brasil \\ E-mail: andressarsilva@hotmail.com \\ lury Teixeira de Sevilha Gosling \\ Mestrando em Administração pela Universidade Federal de Minas Gerais - UFMG. \\ Belo Horizonte, MG, Brasil \\ E-mail: iurygosling@gmail.com
}

\section{RESUMO}

O objetivo deste estudo foi identificar e analisar os fatores que têm relação direta e positiva com a intenção de uso de plataformas de streaming de vídeos pagas, e com o consumo de entretenimento nestas plataformas. Para isso, foi realizada uma pesquisa quantitativa por meio de um survey online que obteve 207 respondentes válidos. Os dados coletados foram analisados estatisticamente com os softwares SPSS e SmartPLS. Concluiu-se que o consumo de entretenimento audiovisual foi desviado das redes de televisão para as plataformas streaming. Os fatores determinantes desse movimento foram a expectativas de desempenho, a influência social, a motivação hedônica, o preço e o custo de troca. Os consumidores pretendem continuar comprando esses serviços no futuro e usá-lo frequentemente no seu diaa-dia. Curiosamente, os fatores tecnológicos, a facilidade de uso e expectativa de desempenho não foram fatores imprescindíveis desse deslocamento.

Palavras-chave: Streaming. Consumo de Entretenimento. Intenção de Uso. UTAUT 2.

\section{ABSTRACT}

The objective of this study was to identify and analyze the factors that have a direct and positive relationship with the intention to use paid video streaming platforms and the consumption of entertainment on these platforms. For this, a quantitative survey was conducted through an online survey that obtained 207 valid respondents. The data collected were statistically analyzed with SPSS and SmartPLS software. It is concluded that the consumption of audiovisual entertainment has been diverted from television networks to streaming platforms. The determinants of this movement were performance expectations, social influence, hedonic motivation, price and exchange cost. Consumers want to continue to buy these services in the future and use them frequently in their daily lives. Interestingly, the technological factors, the ease of use and expectation of performance were not essential factors of this displacement.

Keywords: Streaming. Entertainment Consumption. Intention to Use. UTAUT 2.

Data de aprovação: 22 de agosto de 2018.

Data de submissão: 19 de junho de 2018 


\section{INTRODUÇÃO}

O modo pelo qual os brasileiros consomem entretenimento televisivo tem sido modificado ao longo dos anos desde que esse hábito foi inserido na sociedade, com a invenção da televisão na década de 1920 (CAMARGO, 2009). Tem ocorrido uma migração do consumo de TV aberta para plataformas digitais, e possivelmente no futuro, uma substituição, já que se tornou possível o acesso e o consumo de filmes e séries através das redes online, mais especificamente com o streaming.

O streaming, que pode ser traduzido diretamente do inglês como "transmissão", é uma forma de distribuição de dados em rede, utilizado com grande frequência para a transmissão de diversos arquivos multimídia por meio da internet sem a necessidade de armazenamento do conteúdo pelo usuário em sua própria máquina (COUTINHO, 2014). Além disso, esta não necessidade de download possibilita que a transmissão de conteúdo não infrinja direitos autorais (CAPANEMA; FRANÇA, 2013).

As mudanças tecnológicas ocorridas a partir da primeira década do século XXI alteraram a relação do ser humano com o campo do audiovisual (ROSSINI; RENNER, 2015). O aumento da relação do consumidor com a tecnologia é também um fator que abre portas para o uso da tecnologia streaming. Por se tratar de uma tecnologia inserida no contexto de consumo, a aceitação e o uso das tecnologias de streaming de vídeos pagas podem ser testadas pelo modelo adaptado da Teoria Unificada de Aceitação e Uso de Tecnologia 2 (UTAUT 2). Neste sentido, este modelo teórico foi utilizado para testar a validade de seus construtos no contexto de plataformas de streaming de vídeos.

A pesquisa tem como objetivo geral entender quais são os fatores de desempenho das plataformas de streaming que influenciam no consumo de entretenimento de seus clientes. O teste de validade dos construtos do modelo UTAUT 2 foi utilizado para confirmar o uso e a aceitação de plataformas de streaming pagas por consumidores brasileiros. Para atingir o objetivo geral do estudo, foram delineados os seguintes objetivos específicos: caracterizar os respondentes da pesquisa quantitativa, averiguar a confiabilidade e a validade dos construtos "expectativa de desempenho", "expectativa de esforço", "influência social", "facilidade", "motivação hedônica", "preço", "tecnologia" e "consumo de entretenimento" quando aplicados ao tema do trabalho em questão, e avaliar a influência de cada um dos construtos mencionados anteriormente à intenção de uso das plataformas de streaming de vídeos pagas. A pergunta de pesquisa a se responder é: "Que fatores de desempenho das plataformas de streaming pagas influenciam no consumo de entretenimento de seus clientes?". 


\section{REFERENCIAL TEÓRICO}

A revisão de literatura a seguir tem o objetivo de esclarecer conceitos e aspectos importantes que são pano de fundo da pergunta de pesquisa. Entender o que é streaming, seu retrospecto histórico e sua posição na atualidade no mercado de produtos e serviços voltados ao entretenimento é essencial. Por se tratar de um novo tipo de tecnologia, se torna necessário compreender como a existência desse tipo de plataforma impacta o mercado de entretenimento, principalmente o televisivo.

\section{Streaming e conectividade}

Streaming é uma tecnologia que permite a transmissão instantânea de informação e conteúdo audiovisual através de redes. Essa tecnologia quando utilizada por sites e empresas que disponibilizam filmes, documentários, séries e até mesmo músicas, faz com que o usuário possa ter acesso a todo conteúdo digital sem a necessidade de fazer download (COUTINHO, 2014). As mídias ficam temporariamente armazenadas em cache nos sistemas computacionais e são reproduzidas a medida que o usuário a recebe por meio de transmissão de dados, sendo possível que a transmissão seja ao vivo (live) ou previamente gravada (on demand) (SANTOS, 2014). A transmissão on demand é a mais utilizada nas plataformas de streaming alvo desta pesquisa, uma vez que essas empresas disponibilizam filmes e séries de grande popularidade para serem assistidos instantaneamente, mediante o pagamento de uma mensalidade.

O streaming é um exemplo de tecnologia que possibilitou que a recepção de conteúdo não fosse mais passiva, uma vez o telespectador tem o poder de escolher o momento em que aquele conteúdo será consumido, pode fazer pausas na transmissão e pode filtrar qual dos conteúdos disponibilizados será assistido. (BARBOZA; SILVA, 2014). O streaming gravado é uma das formas mais utilizadas e tradicionais de compartilhamento de conteúdo na internet, e esta popularidade está relacionada principalmente à liberdade de escolha do internauta (GUTMANN; CERQUEIRA, 2016).

Segundo Barboza e Silva (2014), a plataforma de streaming de vídeos Netflix baseia seu sucesso basicamente no fato de ser ao mesmo tempo on demand e multiplataforma. A empresa fez uma lógica inversa da televisão e permitiu que seu consumidor, individualmente, escolhesse como assistir seus filmes e séries preferidos. De acordo com a reportagem da Revista Info, publicada em outubro de 2013, a Netflix é responsável por cerca de um terço do tráfego de internet no horário nobre (22 horas) nos Estados Unidos.

\section{Comportamento do consumidor e consumo de entretenimento}

Os conceitos fundamentais do consumo são satisfação, valor e utilidade. No entanto, na era digital da informação, do conhecimento e da economia de serviços, o elemento principal explicativo do comportamento dos consumidores é a experiência de consumo (NUNES, 2015). A grande velocidade com que novos produtos são criados gera uma necessidade criativa mercadológica, e faz com que empresas busquem alternativas inovadoras para vender produtos tradicionais, como é o caso da Netflix (HERMANN, 2012). As plataformas de streaming pagas são um bom exemplo de adaptação de venda de um conteúdo tido 
como tradicional, focado na experiência de consumo, fator essencial de satisfação do consumidor nos tempos atuais.

Essa percepção é evidenciada pela assinatura de plataformas de streaming de vídeos. O consumidor, mediante o pagamento de uma mensalidade, possui um login e uma senha para acessar uma página na web, e por meio dela ter acesso a vídeos que serão assistidos através de uma transmissão on demand. Para Hermann (2012), essa prática traz maior comodidade na aquisição dos produtos, rapidez na entrega, que passa a ser instantânea, ampla oferta de produtos disponíveis, e benefícios financeiros.

Já existem sinais de que a Netflix, plataforma de streaming de vídeos paga, está mudando a maneira com que a TV convencional é assistida, e a explicação é simples: o serviço oferecido de streaming permite que o telespectador decida quando, onde e como o seu filme ou série favorita será assistido. Além disso, a empresa é também produtora de parte da programação e sai na frente quando o consumidor está interessado em adquirir esse conteúdo exclusivo, já que libera a série na íntegra, e o consumidor não precisa aguardar até a próxima semana para conhecer o desenrolar da trama, como normalmente ocorre na TV convencional (BARBOZA; SILVA, 2014).

\section{Teoria Unificada de Aceitação e Uso de Tecnologia (UTAUT e UTAUT 2)}

A teoria unificada de aceitação e uso da tecnologia foi criada pelos autores Venkatesh, Morris, Davis e Davis (2003) como uma síntese de outros oito modelos desenvolvidos e utilizados para explicar o uso e a aceitação da tecnologia na sociedade (ALVES; PEREIRA, 2014). O UTAUT é um modelo que já foi utilizado em várias pesquisas focadas em entender a adoção de um produto ou serviço tecnológico por um determinado grupo de pessoas (INDRAWATI; HARYOTO, 2015). No entanto, por estar contextualizado no meio organizacional, o UTAUT por si só não cobria a necessidade de aplicação sob o contexto do consumo (FARIA et al., 2014).

Diante da limitação da utilização do modelo UTAUT em pesquisas com foco sobre o comportamento do consumidor, Venkatesh, Thong e Xu (2012) publicaram um novo estudo que aprimorou e preencheu a lacuna do primeiro modelo, sendo este o UTAUT 2 (FARIA et al., 2014), utilizado nesta pesquisa, com o objetivo de testar a validade de seus construtos quando inseridos em um contexto de plataformas de streaming de vídeos pagas.

O modelo UTAUT 2 foi composto de três construtos adicionais ao primeiro modelo, sendo eles: Motivação Hedônica, Valor do Preço e Experiência e Hábito (VENKATESH; THONG; XU, 2012). Nesta pesquisa, o construto Experiência e Hábito foi adaptado para Consumo de Entretenimento a fim de trazer uma nova contribuição ao tema.

Segundo Moraes et al. (2014), o construto Expectativa de Desempenho mede a percepção do utilizador da tecnologia quanto a contribuição dela para o desempenho de seu trabalho. A Expectativa de Esforço seria o grau de facilidade, no ponto de vista do consumidor, relacionado ao uso da tecnologia. A Influência Social seria o grau de influência de pessoas relevantes no círculo social do consumidor sobre o uso da determinada tecnologia. A Facilidade é um construto que verifica a existência e o nível de qualidade de uma infraestrutura técnica e organizacional que contribuem para uso da tecnologia. 
Entre os construtos adicionados pelo modelo UTAUT 2, a Motivação Hedônica seria o prazer e a diversão que o consumidor sente ao utilizar a tecnologia. O Valor do Preço seria a percepção de custo benefício do consumidor ao utilizar a tecnologia, levando em conta o dispêndio financeiro necessário e as vantagens oferecidas pelo produto/sistema/plataforma. Por fim, o Hábito é o construto que mede o modo como as pessoas passam a adotar comportamentos automáticos, devido ao hábito e aprendizagem (MORAES et al., 2014).

\section{Expectativa de Desempenho}

Kit (2014) afirmam que o construto Expectativa de Desempenho mede o grau em que os usuários são beneficiados com o uso de uma tecnologia durante a realização de atividades. A expectativa de desempenho é revelada como um fator significativo da intenção comportamental.

Venkatesh et al. (2003) definiram a Expectativa de Performance, ou Expectativa de Desempenho, como uma forma de medir os ganhos de performance no trabalho que o indivíduo tem ao utilizar a determinada tecnologia.

\section{Expectativa de Esforço}

Expectativa de Esforço é o grau de facilidade encontrado ao utilizar a tecnologia, tendo este construto também uma influência positiva na intenção comportamental no modelo de adoção da tecnologia (KIT, 2014).

Davis (1989), afirma que, mesmo que o utilizador da tecnologia acredite que a aplicação é útil, ao mesmo tempo deve haver a crença de que os benefícios de performance obtidos pelo uso superam a dificuldade de utilizar a aplicação, e isto é resumido no construto Perceived Ease of Use/Facilidade de uso percebida que é definido como "o grau em que uma pessoa acredita que a utilização de um sistema específico seria livre de esforço".

Segundo Vera (2014), o construto Expectativa de Esforço é relevante tanto em pesquisas em que a adoção da tecnologia é compulsória, tanto quando se dá de forma voluntária pelo usuário.

\subsubsection{Influência Social}

Influência Social é a percepção individual de que outras pessoas significativas acreditam que o indivíduo em questão deveria adotar o uso da tecnologia (KIT, 2014). Na criação do modelo UTAUT 2, os autores perceberam que o construto Influência Social é levemente impactante na intenção de uso de tecnologias mandatórias ao usuário. Foi percebido que, neste contexto, o usuário é incentivado ao uso da tecnologia por seus gestores e companheiros de trabalho, o que aumenta a intenção de uso da tecnologia. Para os casos em que a adoção da tecnologia é voluntária, o estudo indicou que o construto Influência Social não é significante (VERA, 2014).

A influência social está relacionada com normas e circunstâncias sociais que afetam no comportamento individual e no processo de julgamento do indivíduo (BONN et al., 2015). Esta influência é criada através de sinais e mensagens que ajudam a formar a consciência de valores de certos produtos, atividades e tecnologias (BONN et al., 2015). 
Condições Facilitadoras

Segundo Mathur e Dhulla (2014), o construto Condições Facilitadoras mede o grau com que o indivíduo acredita que a empresa possui uma infraestrutura técnica para auxiliar o uso do sistema tecnológico. Condições Facilitadoras no contexto de tecnologia seriam fatores objetivos que tornam a ação mais fácil de ser realizada, como por exemplo, a existência de suporte para os usuários de PC (THOMPSON; HIGGINS; HOWELL, 1991).

\section{Motivação Hedônica}

A Motivação Hedônica pode ser definida como uma motivação intrínseca, como prazer e diversão ao utilizar a tecnologia para o seu próprio bem. Conforme os autores do modelo UTAUT 2, o construto Motivação Hedônica tem sido encontrado em pesquisas de Sistemas da Informação, com o nome Prazer Percebido e é um grande influenciador do uso e aceitação da tecnologia (VERA, 2014). Segundo Vera (2014), este construto também foi localizado no contexto do comportamento do consumidor como grande determinante da utilização e aceitação da tecnologia.

Valor de Preço

O construto Valor de Preço pode ser definido como o trade off cognitivo dos usuários entre os benefícios aparentes das tecnologias e os custos econômicos para a aquisição delas, porque, em geral, as pessoas optam por produtos e serviços quando o benefício trazido por eles é maior do que o valor monetário despendido na compra (ALAZZAM et al., 2016).

Este construto foi adicionado ao modelo UTAUT 2, pois uma diferença relevante entre o uso da tecnologia no meio organizacional e o uso do consumidor é o dispêndio monetário do consumidor para utilizar a tecnologia (VERA, 2014). Para os autores do modelo, a percepção do preço e dos custos para a utilização da tecnologia podem ter um significativo impacto sobre o uso dos consumidores, sendo que o impacto é positivo quando o usuário obtém com a utilização da tecnologia benefícios maiores do que o custo e o valor monetário despendido (VERA, 2014).

Hábito

O Hábito tem sido conhecido como o grau com que os usuários se inclinam para implementar comportamentos rotineiros no aprendizado. Este é um dos mais fortes preditores do uso da tecnologia futura (ALAZZAM et al., 2016). Para Mathur e Dhulla (2014), esse construto pode ser definido como "comportamento".

O construto pode ser também chamado de Experiência e Hábito e foi adicionado ao UTAUT 2, pois já era utilizado em pesquisas anteriores sobre o uso da tecnologia (VERA, 2014). O "Hábito" é uma forma de medição do quanto às pessoas tendem a adotar comportamentos automáticos devido ao aprendizado, 
enquanto a "experiência" corresponde à operacionalização da passagem do tempo consequentemente à utilização de uma tecnologia por um indivíduo (VERA, 2014).

Intenção Comportamental e Intenção de Uso

A Intenção Comportamental é a intenção de um indivíduo em realizar um determinado ato que pode predizer comportamentos correspondentes quando este indivíduo age voluntariamente. Esse construto mede também a probabilidade subjetiva de realização de comportamento, bem como a causa de determinado comportamento de uso. Diante disso, as intenções mostram os fatores motivacionais que influenciam o comportamento e são indicativos de quão forte os usuários tentam engajar esse comportamento, assim como quanto esforço é feito para que isso aconteça (KIT, 2014).

A intenção de uso ou comportamento de uso é derivada da intenção comportamental e para analisála devem ser introduzidos critérios de tempo, frequência e comportamento de uso (HUANG; KAO, 2015).

\section{METODOLOGIA}

Em marketing, sempre que um novo problema de pesquisa for observado, deve haver uma pesquisa qualitativa adequada anteriormente à pesquisa quantitativa (MALHOTRA, 2004). Diante disso, a pesquisa em questão seguiu uma abordagem mista, composta de uma pesquisa inicial qualitativa, feita mediante entrevistas de sete usuários de plataformas de streaming de vídeos pagas, e posteriormente de uma pesquisa quantitativa, aplicada por meio de um questionário online.

Esta pesquisa é classificada como descritiva, pois pretende entender quais são os fatores de desempenho das plataformas de streaming pagas que influenciam no consumo de entretenimento de seus clientes. As pesquisas descritivas têm como objetivo principal a descrição das características de determinado fenômeno, população ou experiência (GIL, 2008).

\section{Fase qualitativa}

Para estudar a aplicabilidade do modelo teórico UTAUT 2 especificamente no contexto das plataformas de streaming de vídeos pagas foram realizadas entrevistas com usuários desse tipo de plataformas, a fim de compreender a opinião deles quanto a pontos positivos e negativos da plataforma utilizada, fatores que levariam ao término do relacionamento com a empresa, uso de plataformas concorrentes, e mudança nos hábitos de consumo devido ao uso de plataformas de streaming de vídeos pagas.

Para Gil (2008), a entrevista é uma técnica de pesquisa eficiente para a obtenção aprofundada de dados referentes ao comportamento humano. Por ser uma técnica flexível, que permite a adaptação da condução da entrevista à cada entrevistado e circunstância (GIL, 2008), esta fase inicial da pesquisa foi importante para o esclarecimento de questões pontuais sobre o assunto e obtenção de respostas chaves. Após a análise das entrevistas, notou-se que aspectos emergentes do contexto das plataformas de streaming de vídeos pagas se destacaram no discurso dos entrevistados. As categorias "Tecnologia" e "Consumo de 
Entretenimento" estiveram bastantes presentes nas entrevistas e se configuraram como um resultado da etapa qualitativa. Neste sentido, devido a isso, tais construtos foram incorporados ao modelo teórico UTAUT 2. Foram desenvolvidas escalas específicas para tais construtos e os mesmos foram mensurados no estudo quantitativo.

Foram realizadas sete entrevistas na fase qualitativa, considerando um roteiro único, focado em entender melhor a opinião de usuários de plataformas de streaming de vídeos pagas. A seguir estão as perguntas utilizadas nas entrevistas:

1. Em sua opinião, quais são os pontos fortes da Netflix? Por que você gosta da plataforma?

2. O que você não gosta na Netflix? Desenvolva.

3. O que te levaria a não utilizar mais a plataforma? Você já fez uso de alguma plataforma semelhante? Se sim, qual?

4. Você acredita que o uso da Netflix modificou seus hábitos de consumo? Se sim, detalhe os motivos e as mudanças ocorridas.

\section{Fase quantitativa}

Os dados quantitativos foram coletados por meio de um survey online disponibilizado na plataforma Google Forms entre os dias 09 e 14 de setembro de 2016. A pesquisa teve 256 respostas, dos quais 49 foram descartados por não atenderem aos objetivos da pesquisa. A técnica bola de neve foi utilizada para promoção do questionário, em que os respondentes colaboraram para a divulgação. O questionário foi a princípio anunciado pela pesquisadora em redes sociais, e posteriormente houve a replicação da divulgação por alguns respondentes da pesquisa.

Para determinar a quantidade mínima necessária de respondentes foi calculado cinco vezes o número de variáveis presentes no estudo. Como o questionário aplicado possui 40 variáveis a amostra mínima deveria ser de 200 indivíduos, número que foi superado.

O questionário iniciava com a pergunta-filtro, para determinar se o respondente era elegível à pesquisa. Quando a resposta era negativa, a pesquisa era encerrada com uma mensagem de agradecimento. No caso afirmativo o questionário prosseguia para a primeira variável da pesquisa, além de três perguntas sobre dados demográficos (idade, sexo e grau de escolaridade). Foi utilizada a escala tipo Likert de 0 a 10 , sendo que 0 correspondeu a "discordo totalmente", 5 foi o ponto neutro, e 10 correspondeu a "concordo totalmente" (Quadro 1). 
Quadro 1 - Questionário da fase quantitativa com construtos, indicadores e referências

continua

\begin{tabular}{|c|c|c|c|}
\hline Construto & Cód. & Indicador & Referência \\
\hline \multirow{5}{*}{$\begin{array}{l}\text { Expectativa de } \\
\text { Desempenho }\end{array}$} & ED1 & A plataforma é indispensável para o consumo de entretenimento & \multirow{3}{*}{$\begin{array}{l}\text { Venkatesh, Thong e Xu } \\
\text { (2012) }\end{array}$} \\
\hline & ED2 & $\begin{array}{l}\text { Nessa plataforma, eu tenho mais chances de encontrar o programa } \\
\text { que estou procurando }\end{array}$ & \\
\hline & ED3** & A plataforma melhora a experiência de assistir filmes e séries ${ }^{\star *}$ & \\
\hline & ED4 & Sempre encontro conteúdo vasto e diversificado na plataforma & \multirow[b]{2}{*}{ Pesquisa qualitativa } \\
\hline & ED5** & \begin{tabular}{|l}
$\begin{array}{l}\text { As atualizações de programação da plataforma são } \\
\text { constantes }\end{array}$ \\
\end{tabular} & \\
\hline \multirow{3}{*}{$\begin{array}{l}\text { Expectativa de } \\
\text { Esforço* }\end{array}$} & EE1 & $\begin{array}{l}\text { Tenho facilidade em localizar o filme/série que estou procurando } \\
\text { na plataforma }\end{array}$ & \multirow{3}{*}{$\begin{array}{l}\text { Venkatesh, Thong e Xu } \\
(2012)\end{array}$} \\
\hline & EE2 & O processo de contratação da plataforma é simples & \\
\hline & EE3 & Não sofro dificuldades em me conectar à plataforma & \\
\hline \multirow{3}{*}{$\begin{array}{l}\text { Influência } \\
\text { Social }\end{array}$} & IS1** & Fui influenciado pelos meus amigos a utilizar a plataforma** & \multirow{3}{*}{$\begin{array}{l}\text { Venkatesh, Thong e Xu } \\
(2012)\end{array}$} \\
\hline & IS2 & Pessoas que considero influentes indicam o uso da plataforma & \\
\hline & IS3 & Sinto-me socialmente incluído por utilizar a plataforma & \\
\hline \multirow{4}{*}{$\begin{array}{l}\text { Facilidade de } \\
\text { Uso* }\end{array}$} & $\mathrm{F} 1$ & Eu tenho os recursos necessários para me conectar à plataforma & \multirow{2}{*}{$\begin{array}{l}\text { Venkatesh, Thong e Xu } \\
(2012)\end{array}$} \\
\hline & F2 & Eu tenho o conhecimento necessário para utilizar a plataforma & \\
\hline & F3 & $\begin{array}{l}\text { Consigo acessar a plataforma de qualquer dispositivo com acesso } \\
\text { à internet. }\end{array}$ & Pesquisa qualitativa \\
\hline & F4 & $\begin{array}{l}\text { Tenho o suporte necessário quando enfrento problemas com a } \\
\text { plataforma }\end{array}$ & \multirow{4}{*}{$\begin{array}{l}\text { Venkatesh, Thong e Xu } \\
(2012)\end{array}$} \\
\hline \multirow{3}{*}{$\begin{array}{l}\text { Motivação } \\
\text { Hedônica }\end{array}$} & $\mathrm{MH} 1$ & Eu gosto de usar a plataforma & \\
\hline & $\mathrm{MH} 2$ & Usar a plataforma é agradável & \\
\hline & $\mathrm{MH} 3$ & Usar a plataforma é muito divertido & \\
\hline \multirow{6}{*}{ Preço } & $\mathrm{P} 1$ & O valor da mensalidade da plataforma é justo & \multirow{2}{*}{$\begin{array}{l}\text { Venkatesh, Thong e Xu } \\
(2012)\end{array}$} \\
\hline & P2 & Compensa pagar a mensalidade e ter acesso ilimitado à plataforma & \\
\hline & P3 & $\begin{array}{l}\text { Eu permaneceria sendo cliente desta plataforma mesmo com um } \\
\text { aumento considerável da mensalidade }\end{array}$ & Pesquisa qualitativa \\
\hline & P4 & A mensalidade da plataforma é barata & $\begin{array}{l}\text { Venkatesh, Thong e Xu } \\
\text { (2012) }\end{array}$ \\
\hline & P5 & $\begin{array}{l}\text { Eu não trocaria essa plataforma por uma plataforma semelhante } \\
\text { mais barata }\end{array}$ & \multirow[t]{2}{*}{ Pesquisa qualitativa } \\
\hline & P6 & Eu não tenho interesse em buscar por plataforma alternativa & \\
\hline
\end{tabular}


Quadro 1 - Questionário da fase quantitativa com construtos, indicadores e referências

continuação

\begin{tabular}{|c|c|c|c|}
\hline Construto & Cód. & Indicador & Referência \\
\hline \multirow{7}{*}{ Tecnologia* } & & Essa plataforma de streaming: & \\
\hline & $\mathrm{T} 1$ ** & $\begin{array}{l}\text { Permite que eu assista meus programas favoritos em qualquer } \\
\text { lugar** }\end{array}$ & \multirow{6}{*}{ Pesquisa qualitativa } \\
\hline & T2 & Permite a criação de perfis dentro de uma única conta & \\
\hline & T3** & Possibilita a utilização de telas simultâneas ${ }^{* *}$ & \\
\hline & T4 & Permite customizar as preferências em cada um dos perfis & \\
\hline & T5 & Raramente apresenta problemas de conectividade ${ }^{* *}$ & \\
\hline & T6** & Possibilita o mesmo acesso em qualquer lugar do mundo** & \\
\hline \multirow{7}{*}{$\begin{array}{l}\text { Consumo de } \\
\text { Entretenimento }\end{array}$} & CE1** & $\begin{array}{l}\text { Assistir a plataforma é minha primeira opção de } \\
\text { entretenimento desse tipo** }\end{array}$ & \\
\hline & CE2** & $\begin{array}{l}\text { Eu passei a frequentar menos cinemas depois de assinar a } \\
\text { plataforma** }\end{array}$ & \multirow{3}{*}{ Pesquisa qualitativa } \\
\hline & CE3 ${ }^{* *}$ & $\begin{array}{l}\text { Depois do lançamento da plataforma, a TV a cabo passou a } \\
\text { ser um item dispensável** }\end{array}$ & \\
\hline & CE4 & Eu deixei de assistir televisão após utilizar a plataforma & \\
\hline & CE5 & Eu sou viciado nessa plataforma & \multirow{2}{*}{$\begin{array}{l}\text { Venkatesch, Thong e Xu } \\
(2012)\end{array}$} \\
\hline & CE6 & $\begin{array}{l}\text { Eu gasto meu tempo livre praticamente inteiro com essa } \\
\text { plataforma }\end{array}$ & \\
\hline & CE7 & $\begin{array}{l}\text { Mudei meus hábitos de consumo desse tipo de entretenimento } \\
\text { depois dessa plataforma }\end{array}$ & Pesquisa qualitativa \\
\hline \multirow{3}{*}{$\begin{array}{l}\text { Intenção de } \\
\text { Uso }\end{array}$} & IU1 & Eu pretendo continuar usando essa plataforma no futuro & \multirow{3}{*}{$\begin{array}{l}\text { Venkatesch, Thong e Xu } \\
(2012)\end{array}$} \\
\hline & IU2 & Eu permanecerei utilizando essa plataforma diariamente & \\
\hline & IU3 & Eu planejo continuar utilizando a plataforma frequentemente & \\
\hline
\end{tabular}

${ }^{*}$ Construtos não significativos como antecedentes do consumo de entretenimento.

**Variáveis indicadoras excluídas do modelo a partir da AFE.

Fonte: Elaborado pelos autores.

As hipóteses testadas neste estudo foram:

$\mathrm{H}_{1}$ : A influência social impacta positivamente no consumo de entretenimento;

$\mathrm{H}_{2}$ : O preço impacta positivamente no consumo de entretenimento;

$\mathrm{H}_{3}$ : A expectativa de desempenho impacta positivamente no consumo de entretenimento;

$\mathrm{H}_{4}$ : A expectativa de esforço impacta positivamente no consumo de entretenimento;

$\mathrm{H}_{5}$ : A facilidade de uso impacta positivamente no consumo de entretenimento;

$\mathrm{H}_{6}$ : O consumo de entretenimento impacta positivamente na intenção de uso;

$\mathrm{H}_{7}$ : A motivação hedônica impacta positivamente no consumo de entretenimento;

$\mathrm{H}_{8}$ : A tecnologia impacta positivamente no consumo de entretenimento;

$\mathrm{H}_{9}$ : O custo de troca impacta positivamente no consumo de entretenimento. 


\section{ANÁLISE DOS DADOS}

\section{Análise qualitativa}

As entrevistas foram realizadas com sete usuários de uma plataforma de streaming de vídeos paga específica. Segue, no Quadro 2, o perfil dos respondentes.

Quadro 2 - Perfil dos entrevistados na fase qualitativa

\begin{tabular}{|l|l|l|l|l|}
\hline \multicolumn{1}{|c|}{ Nome } & \multicolumn{1}{|c|}{ Gênero } & \multicolumn{1}{c|}{ Idade } & \multicolumn{1}{c|}{ Profissão } & \multicolumn{1}{c|}{ Tipo de relacionamento com a plataforma } \\
\hline Entrevistado A & Feminino & 22 anos & Estudante & Por volta de 3 anos \\
\hline Entrevistado B & Feminino & 23 anos & Estudante & Por volta de 1 ano \\
\hline Entrevistado C & Feminino & 24 anos & Advogada & Por volta de 2 anos \\
\hline Entrevistado D & Masculino & 23 anos & Estudante & 1 ano e meio \\
\hline Entrevistado E & Feminino & 23 anos & Advogada & 2 anos \\
\hline Entrevistado F & Feminino & 52 anos & Dona de casa & Por volta de 1 ano \\
\hline Entrevistado G & Feminino & 23 anos & Estudante & 4 meses \\
\hline
\end{tabular}

Fonte: Elaborado pelos autores

Em relação aos pontos fortes da plataforma de streaming em questão, no ponto de vista dos entrevistados, notou-se que as respostas foram bastante semelhantes. Os pontos mencionados foram praticidade, preço justo, custo benefício, mobilidade, facilidade de acesso, variedade, possibilidade de compartilhamento da conta e segurança. Várias dessas vantagens estiveram presentes na fala de mais de um dos sete entrevistados.

Quanto aos pontos que os respondentes não gostam da plataforma em questão, os resultados também foram homogêneos. A demora na atualização dos filmes foi quase unânime, sendo citada por seis dos sete usuários entrevistados. Outros pontos mencionados foram a disparidade com a mesma plataforma em outros países, como os Estados Unidos, que possui uma cartela de conteúdo mais completa e frequentemente atualizada, a dificuldade em localizar o filme desejado, a lentidão, e o acesso vinculado à localidade do acesso, fazendo com que a utilização da plataforma seja prejudicada em viagens, por exemplo.

Foi percebido que a maioria dos entrevistados não faz uso de plataformas de streaming de vídeo além da Netflix. Entre os motivos que levariam aos entrevistados a não utilizar mais a plataforma, o mais mencionado foi o aumento do preço e a criação de um concorrente semelhante, com qualidade igual ou superior. Todos os entrevistados fizeram menção em pelo menos um desses pontos durante a resposta da pergunta três.

A última pergunta realizada na entrevista foi essencial para a criação do construto "Hábito de Consumo" inserido no questionário da fase quantitativa da pesquisa. Os entrevistados, em sua maioria reconheceram alguma mudança em seus hábitos de consumo de entretenimento causada pela utilização da plataforma de streaming de vídeos paga em questão. 


\section{Análise quantitativa}

\section{Caracterização da amostra}

A amostra total obtida na pesquisa foi de 256 respondentes, dos quais 49 foram descartados por não atenderem aos objetivos da pesquisa - trinta e quatro pessoas disseram não utilizarem plataformas de streaming de vídeos pagas e houve quinze outliers. Sendo assim, chegou-se ao número final de 207 respondentes válidos. A representatividade por gênero ficou assim constatada: 175 foram do gênero feminino, o que representa $84,54 \%$ do total, enquanto 32 do gênero masculino, representando $15,46 \%$ da amostra. Como exposto, houve uma diferença numérica significativa a favor das mulheres, fato que não é passível de justificativa aparente, já que a prospecção dos respondentes foi realizada de modo aleatório.

Outro dado importante é em relação à faixa etária da amostra. A grande maioria dos participantes possui entre 18 e 24 anos. Além disso, o segundo grupo é o de indivíduos com 25 até 35 anos, e o terceiro é o de indivíduos com até 17 anos, o que demonstra predominância de jovens entre os respondentes. Apenas 0,97\% das pessoas têm acima de 51 anos. Esses resultados podem indicar a faixa etária de maior utilização de plataformas de streaming pagas. Há, entretanto, de se destacar a influência do principal método de obtenção de respondentes da pesquisa, que foi a rede social. A proeminência de indivíduos mais jovens pode ser explicada, em parte, pois são eles que utilizam em maior número as redes sociais.

Em relação ao grau de escolaridade dos respondentes, percebeu-se uma grande concentração entre as faixas mais altas - Ensino superior incompleto e completo - que juntas representam $77,29 \%$. Esses resultados não podem ser relacionados diretamente ao objeto de pesquisa, mas sim ao meio em que o questionário foi veiculado.

Análise de Outliers Uni e Multivariados, Normalidade, Linearidade e Estatísticas Descritivas

A análise da normalidade dos dados é feita com base na curva de distribuição normal ao se comparar os dados de uma determinada amostra com uma distribuição normal com a mesma média e mesmo desvio padrão (HAIR et al., 2014). Os dados não foram normais univariado de acordo com o teste de KolmogorovSmirnov, assim, não existe normalidade multivariada e, por isso, optou-se por estimar o modelo usando o SmartPLS.

Para testar a linearidade, calculou-se a correlação linear par a par, utilizando-se a correlação de Spearman. Avaliou-se a porcentagem de correlações significativas de cada amostra, as quais indicam a presença de dados lineares.

Os outliers são observações atípicas que apresentam uma resposta extrema em uma questão específica ou uma combinação única de respostas, significativamente diferente dos padrões observados pela maioria dos entrevistados (HAIR et al., 2005; 2014). Foram encontrados 15 outliers que foram excluídos da pesquisa.

A Tabela 1 apresenta as estatísticas descritivas dos construtos, de forma a fornecer um panorama geral dos resultados do survey. Para isso, destaca-se que desvios-padrão menores que 1,0 demonstram forte 
coerência nas respostas dos respondentes, sendo que o contrário acontece quando os desvios são maiores que 3,0, o que mostra grande variabilidade de respostas (HAIR et al., 2005).

Tabela 1 - Estatísticas descritivas dos itens dos construtos

\begin{tabular}{|c|c|c|c|c|c|c|}
\hline \multirow{2}{*}{ Questão } & \multicolumn{2}{|c|}{ Número } & \multirow{2}{*}{ Média } & \multirow{2}{*}{ Desvio Padrão } & \multirow{2}{*}{ Mínimo } & \multirow{2}{*}{ Máximo } \\
\hline & Válido & Ausente & & & & \\
\hline ED1 & 207 & 0 & 6,55 & 2,647 & 0 & 10 \\
\hline ED2 & 207 & 0 & 7,18 & 2,161 & 0 & 10 \\
\hline ED3 & 207 & 0 & 9,06 & 1,355 & 0 & 10 \\
\hline ED4 & 207 & 0 & 7,61 & 2,033 & 0 & 10 \\
\hline ED5 & 207 & 0 & 6,98 & 2,295 & 0 & 10 \\
\hline EE1 & 207 & 0 & 8,29 & 1,865 & 2 & 10 \\
\hline EE2 & 207 & 0 & 9,45 & 1,156 & 4 & 10 \\
\hline EE3 & 207 & 0 & 9,32 & 1,291 & 0 & 10 \\
\hline IS1 & 207 & 0 & 6,39 & 3,523 & 0 & 10 \\
\hline IS2 & 207 & 0 & 6,89 & 3,232 & 0 & 10 \\
\hline IS3 & 207 & 0 & 6,60 & 3,376 & 0 & 10 \\
\hline F1 & 207 & 0 & 9,58 & 0,882 & 6 & 10 \\
\hline $\mathrm{F} 2$ & 207 & 0 & 9,68 & 0,896 & 1 & 10 \\
\hline F3 & 207 & 0 & 9,34 & 1,485 & 0 & 10 \\
\hline $\mathrm{F} 4$ & 207 & 0 & 7,75 & 2,150 & 0 & 10 \\
\hline $\mathrm{MH} 1$ & 207 & 0 & 9,64 & 0,769 & 7 & 10 \\
\hline MH2 & 207 & 0 & 9,63 & 0,758 & 6 & 10 \\
\hline MH3 & 207 & 0 & 9,34 & 1,255 & 1 & 10 \\
\hline $\mathrm{P} 1$ & 207 & 0 & 9,23 & 1,270 & 1 & 10 \\
\hline P2 & 207 & 0 & 9,45 & 1,115 & 1 & 10 \\
\hline P3 & 207 & 0 & 6,14 & 2,796 & 0 & 10 \\
\hline P4 & 207 & 0 & 7,97 & 2,210 & 0 & 10 \\
\hline P5 & 207 & 0 & 5,89 & 3,089 & 0 & 10 \\
\hline P6 & 207 & 0 & 6,29 & 3,335 & 0 & 10 \\
\hline T1 & 207 & 0 & 8,45 & 2,135 & 0 & 10 \\
\hline T2 & 207 & 0 & 9,70 & 0,824 & 5 & 10 \\
\hline T3 & 207 & 0 & 8,46 & 2,498 & 0 & 10 \\
\hline T4 & 207 & 0 & 9,38 & 1,320 & 4 & 10 \\
\hline T5 & 207 & 0 & 8,43 & 2,008 & 0 & 10 \\
\hline T6 & 207 & 0 & 7,30 & 3,145 & 0 & 10 \\
\hline CE1 & 207 & 0 & 8,25 & 2,328 & 0 & 10 \\
\hline CE2 & 207 & 0 & 5,46 & 3,628 & 0 & 10 \\
\hline CE3 & 207 & 0 & 6,66 & 3,256 & 0 & 10 \\
\hline CE4 & 207 & 0 & 5,78 & 3,535 & 0 & 10 \\
\hline CE5 & 207 & 0 & 6,17 & 3,365 & 0 & 10 \\
\hline CE6 & 207 & 0 & 4,86 & 3,274 & 0 & 10 \\
\hline CE7 & 207 & 0 & 6,04 & 3,245 & 0 & 10 \\
\hline IU1 & 207 & 0 & 9,38 & 1,138 & 5 & 10 \\
\hline IU2 & 207 & 0 & 6,73 & 2,997 & 0 & 10 \\
\hline IU3 & 207 & 0 & 8,86 & 1,685 & 2 & 10 \\
\hline
\end{tabular}

Fonte: dados da pesquisa. 


\section{Análise Fatorial Exploratória}

A análise fatorial considera a estrutura das inter-relações entre diversas variáveis para definir um conjunto de dimensões latentes comuns, tendo como propósito geral da técnica, resumir a informação de diversas variáveis originais em um conjunto menor de fatores com uma perda mínima de informação (HAIR et al., 2005). Em suma, segundo o autor, o objetivo da análise fatorial é maximizar o poder de explicação do conjunto inteiro de variáveis e para tanto, a técnica deve considerar todas as variáveis simultaneamente.

Dois testes foram utilizados para verificação da adequação da técnica de Análise Fatorial Exploratória, o Teste de Esfericidade de Bartlett (TEB) e o Kaiser-Meyer-Olkin (KMO) - Tabela 2. Primeiramente, o teste de Esfericidade de Bartlett demonstra a existência de relações significativas entre os itens e testa a hipótese nula de que não há correlação significativa entre os itens, sendo, portanto, a matriz de correlação igual à matriz identidade (GOSLING, 2001).

Tabela 2 - Teste TEB e KMO

\begin{tabular}{lrr}
\hline \multicolumn{2}{c}{ Testes } & Resultados \\
\hline Kaiser-Meyer-Olkin Measure of Sampling Adequacy. & 0,802 \\
\hline & Approx. Chi-Square & $2.083,986$ \\
Bartlett's Test of Sphericity & df & 276 \\
& Sig. & 0,000 \\
\hline
\end{tabular}

Fonte: dados da pesquisa.

De acordo com Hair et al. (2005) os parâmetros para a medida KMO de adequação da amostra são, em ordem crescente: até 0,500 - inaceitável; acima de 0,600 - regular; acima de 0,700 - boa; acima de 0,800 - muito boa e acima de 0,900 excelente.

De acordo com Henseler, Ringle e Sinkovics (2009), é necessário garantir que os construtos operacionalizados na pesquisa sejam válidos e confiáveis. Os autores sugerem que se utilize a Análise Fatorial Exploratória (AFE) para assegurar a unidimensionalidade dos construtos. Para tanto, é necessário identificar e reter os fatores com autovalores superiores a 1. Ao realizar a AFE percebeu-se que o construto Preço se dividiu e deu origem a um novo construto, o Custo de Troca - Tabela 3. 
Tabela 3 - Matriz Componente

\begin{tabular}{|c|c|c|c|c|c|c|c|}
\hline \multirow{2}{*}{ Questões } & \multicolumn{7}{|c|}{ Componente } \\
\hline & 1 & 2 & 3 & 4 & 5 & 6 & 7 \\
\hline $\begin{array}{l}\text { ED1 A plataforma é indispensável para o consumo de } \\
\text { entretenimento } \\
\text { ED2 Nessa plataforma, eu tenho mais chances de encontrar o } \\
\text { programa que estou procurando }\end{array}$ & 0,492 & & & & $\begin{array}{l}0,540 \\
0,756\end{array}$ & & \\
\hline ED3 A plataforma melhora a experiência de assistir filmes e séries & & & & & 0,664 & & \\
\hline ED4 Sempre encontro conteúdo vasto e diversificado na plataforma & & 0,406 & & & 0,651 & & \\
\hline IS1 Fui influenciado pelos meus amigos a utilizar a plataforma & & & & & & & 0,782 \\
\hline IS2 Pessoas que considero influentes indicam o uso da plataforma & & & & & & & 0,749 \\
\hline IS3 Sinto-me socialmente incluído por utilizar a plataforma & & & & & & & 0,741 \\
\hline MH1 Eu gosto de usar a plataforma & & & 0,832 & & & & \\
\hline MH2 Usar a plataforma é agradável & & & 0,847 & & & & \\
\hline MH3 Usar a plataforma é muito divertido & 0,309 & & 0,754 & & & & \\
\hline PRE1 O valor da mensalidade da plataforma é justo & & & & 0,865 & & & \\
\hline $\begin{array}{l}\text { PRE2 Compensa pagar a mensalidade e ter acesso ilimitado à } \\
\text { plataforma }\end{array}$ & & & & 0,837 & & & \\
\hline $\begin{array}{l}\text { CT1 Eu permaneceria sendo cliente desta plataforma mesmo com } \\
\text { um aumento considerável da mensalidade }\end{array}$ & & 0,632 & & & & & \\
\hline PRE3 A mensalidade da plataforma é barata & & 0,418 & & 0,511 & & & \\
\hline $\begin{array}{l}\text { CT2 Eu não trocaria essa plataforma por uma plataforma } \\
\text { semelhante mais barata }\end{array}$ & & 0,792 & & & & & \\
\hline $\begin{array}{l}\text { CT3 Eu não tenho interesse em buscar por plataforma } \\
\text { alternativas }\end{array}$ & & 0,821 & & & & & \\
\hline TEC2 Permite a criação de perfis dentro de uma única conta & & & & & & 0,624 & \\
\hline TEC3 Possibilita a utilização de telas simultâneas & & & & & & 0,614 & \\
\hline TEC4 Permite customizar as preferências em cada um dos perfis & & & & & & 0,753 & \\
\hline $\begin{array}{l}\text { CEN3 Depois do lançamento da plataforma, a TV a cabo passou a } \\
\text { ser um item dispensável }\end{array}$ & 0,575 & & & & & 0,450 & \\
\hline CEN4 Eu deixei de assistir televisão após utilizar a plataforma & 0,767 & & & & & & \\
\hline CEN5 Eu sou viciado nessa plataforma & 0,813 & & & & & & \\
\hline $\begin{array}{l}\text { CEN6 Eu gasto meu tempo livre praticamente inteiro com essa } \\
\text { plataforma }\end{array}$ & 0,789 & & & & & & \\
\hline $\begin{array}{l}\text { CEN7 Mudei meus hábitos de consumo desse tipo de } \\
\text { entretenimento depois dessa plataforma }\end{array}$ & 0,748 & & & & & & \\
\hline
\end{tabular}

Fonte: dados da pesquisa. 
Modelo de Mensuração

Para testar o modelo proposto pela pesquisa optou-se pelo uso dos softwares IBM SPSS Statistics e SmartPLS 3.2.4. O modelo de mensuração foi composto pelas medidas de Confiabilidade (simples e composta), pela Validade Convergente (variância média extraída e cargas externas) e pela Validade Discriminante (cargas cruzadas, Fornell-Larcker e Heterotrait-Monotrait Ratio).

Ao realizar a análise dos dados no software SmartPLS, constatou-se a necessidade de exclusão de alguns itens para a melhor adequação do modelo, foram eles: ED3, ED5, IS1, TEC1, TEC3, TEC5, TEC6, CEN1, CEN2 e CEN3.

A análise da confiabilidade é realizada utilizando os valores do Alpha de Cronbach e da confiabilidade composta, obtidos com a análise dos dados no software SmartPLS. Os parâmetros para a análise da confiabilidade composta é o mesmo do Alpha de Cronbach, ou seja, os valores de 0,600 a 0,700 aceitáveis em pesquisas exploratórias; valores entre 0,700 a 0,900 são satisfatórios e acima de 0,900 são indesejados. (HAIR et al. 2014). Como pode ser observado na Tabela 4 os construtos ED, IS e TEC possuem valores de Alpha de Cronbach levemente abaixo do satisfatório, mas ainda aceitáveis em pesquisas exploratórias, além disso, todos os valores da Confiabilidade Composta são adequados.

A AVE é a medida para estabelecer a validade convergente no nível do construto, um valor de AVE igual ou maior que 0,500 indica que, em média, o construto explica mais da metade da variação dos seus indicadores e de acordo com a Tabela 4, todos os valores de AVE são adequados.

Tabela 4 - Confiabilidade Simples e Composta e AVE

\begin{tabular}{lccc}
\hline \multirow{2}{*}{ Construto } & Confiabilidade Simples & Confiabilidade Composta & Variância Média Explicada (AVE) \\
\cline { 2 - 3 } & Alpha de Cronbach & & \\
\hline CEN & 0,851 & 0,899 & 0,693 \\
CT & 0,736 & 0,844 & 0,647 \\
ED & 0,677 & 0,810 & 0,592 \\
INT & 0,700 & 0,823 & 0,611 \\
IS & 0,648 & 0,837 & 0,724 \\
MH & 0,860 & 0,914 & 0,782 \\
PRE & 0,783 & 0,783 & 0,610 \\
TEC & 0,624 & 0,823 & 0,710 \\
\hline
\end{tabular}

Fonte: dados da pesquisa.

Para Hair et al. (2014), todos os valores de cargas externas devem ser maiores que 0,700 , e conforme a Tabela 5 todos os valores de cargas externas dos construtos reflexivos são adequados, exceto PRE3 que está levemente abaixo do adequado - Figura 1. 
Tabela 5 - Cargas Externas

\begin{tabular}{|c|c|c|c|c|c|c|c|c|}
\hline \multicolumn{9}{|c|}{ Cargas Externas } \\
\hline Indicador & CEN & СТ & ED & INT & IS & MH & PRE & TEC \\
\hline CEN4 & 0,728 & & & & & & & \\
\hline CEN5 & 0,909 & & & & & & & \\
\hline CEN6 & 0,882 & & & & & & & \\
\hline CEN7 & 0,801 & & & & & & & \\
\hline CT1 & & 0,778 & & & & & & \\
\hline CT2 & & 0,886 & & & & & & \\
\hline CT3 & & 0,751 & & & & & & \\
\hline ED1 & & & 0,843 & & & & & \\
\hline ED2 & & & 0,764 & & & & & \\
\hline ED4 & & & 0,704 & & & & & \\
\hline \multicolumn{9}{|l|}{ EF1 } \\
\hline \multicolumn{9}{|l|}{ EF2 } \\
\hline \multicolumn{9}{|l|}{ EF3 } \\
\hline \multicolumn{9}{|l|}{ F1 } \\
\hline \multicolumn{9}{|l|}{ F2 } \\
\hline \multicolumn{9}{|l|}{ F3 } \\
\hline \multicolumn{9}{|l|}{ F4 } \\
\hline 12 & & & & & 0,766 & & & \\
\hline INT2 & & & & 0,822 & & & & \\
\hline INT3 & & & & 0,822 & & & & \\
\hline INTE1 & & & & 0,698 & & & & \\
\hline IS3 & & & & & 0,932 & & & \\
\hline MH1 & & & & & & 0,905 & & \\
\hline MH2 & & & & & & 0,912 & & \\
\hline $\mathrm{MH} 3$ & & & & & & 0,830 & & \\
\hline PRE1 & & & & & & & 0,851 & \\
\hline PRE2 & & & & & & & 0,973 & \\
\hline PRE3 & & & & & & & 0,561 & \\
\hline TC4 & & & & & & & & 0,842 \\
\hline TEC2 & & & & & & & & 0,867 \\
\hline
\end{tabular}

Fonte: Saída do Software SmartPLS 
Figura 1 - Modelo de Mensuração

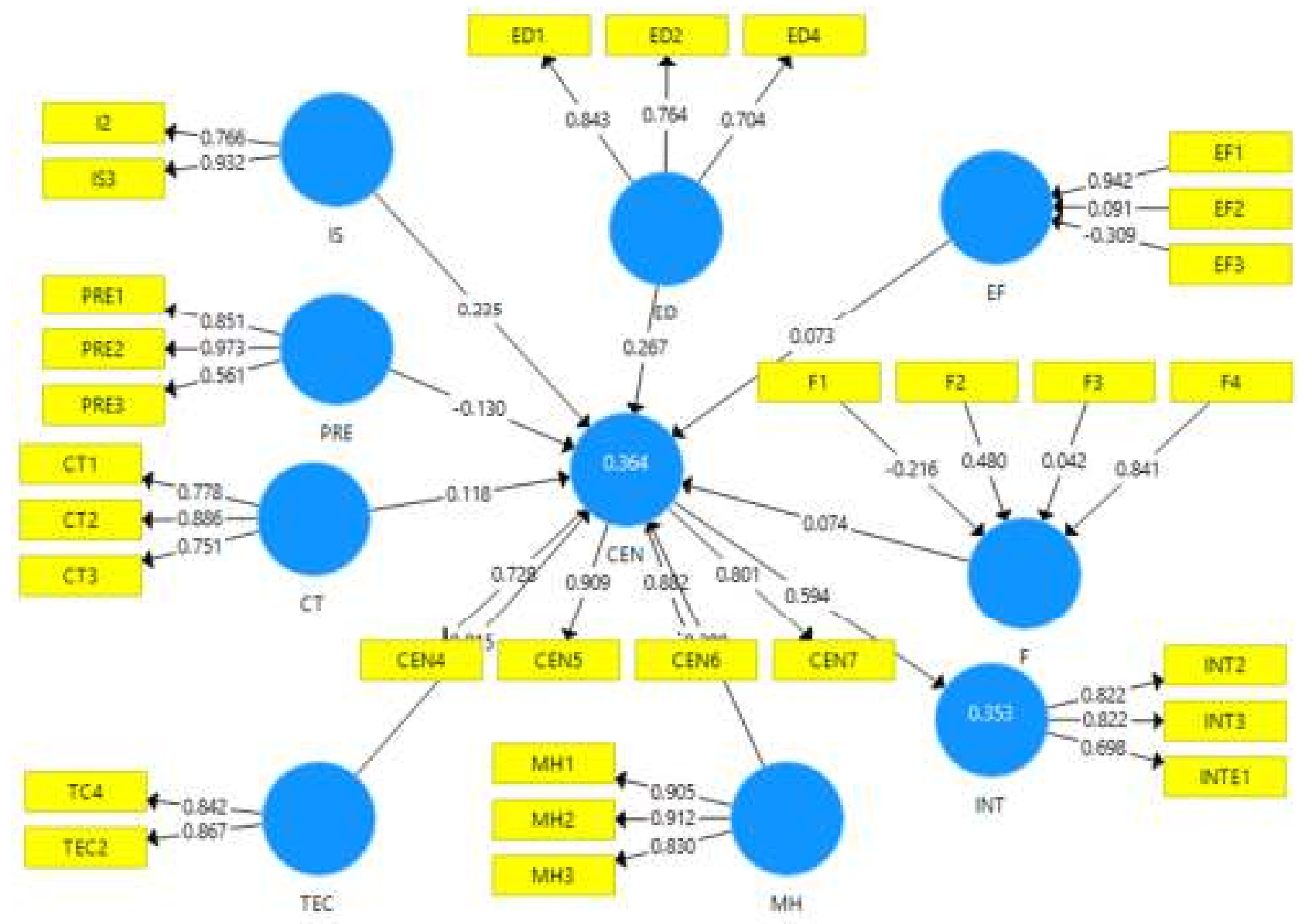

Fonte: dados da pesquisa.

Para a verificação da validade discriminante são usadas as cargas cruzadas, o critério de FornellLarcker e HTMT. Os resultados dessas análises são apresentados nas Tabelas 6, 7 e 8 e, como pode ser confirmado, todos os valores são adequados.

As cargas cruzadas devem ser maiores que todas as outras cargas dos construtos, ou seja, a carga de um indicador sobre o construto associado deve ser maior que todas as cargas desse indicador sobre outros construtos (HAIR et al., 2014). Esse critério estabelece que a variável latente (construto) deve compartilhar mais variância com seus indicadores do que com as outras variáveis latentes (outros construtos do modelo). (HAIR et al., 2014). 
Tabela 6 - Cargas Cruzadas

\begin{tabular}{|c|c|c|c|c|c|c|c|c|c|c|}
\hline \multicolumn{11}{|c|}{ Cargas Cruzadas } \\
\hline Indicador & CEN & $\mathrm{CT}$ & ED & EF & $\mathbf{F}$ & INT & IS & MH & PRE & TEC \\
\hline CEN4 & 0,728 & 0,172 & 0,259 & 0,100 & 0,101 & 0,316 & 0,223 & 0,259 & $-0,007$ & 0,138 \\
\hline CEN5 & 0,909 & 0,354 & 0,446 & 0,169 & 0,314 & 0,622 & 0,309 & 0,431 & 0,207 & 0,153 \\
\hline CEN6 & 0,882 & 0,282 & 0,386 & 0,204 & 0,179 & 0,538 & 0,250 & 0,342 & 0,141 & 0,135 \\
\hline CEN7 & 0,801 & 0,278 & 0,354 & 0,177 & 0,066 & 0,440 & 0,341 & 0,284 & 0,126 & 0,127 \\
\hline CT1 & 0,278 & 0,778 & 0,319 & 0,120 & 0,169 & 0,289 & 0,130 & 0,317 & 0,304 & 0,123 \\
\hline CT2 & 0,328 & 0,886 & 0,411 & 0,163 & 0,147 & 0,322 & 0,132 & 0,211 & 0,223 & 0,055 \\
\hline CT3 & 0,172 & 0,751 & 0,273 & 0,174 & 0,004 & 0,175 & 0,158 & 0,099 & 0,146 & 0,043 \\
\hline ED1 & 0,450 & 0,246 & 0,843 & 0,142 & 0,181 & 0,373 & 0,145 & 0,289 & 0,235 & 0,042 \\
\hline ED2 & 0,250 & 0,369 & 0,764 & 0,208 & 0,045 & 0,286 & 0,156 & 0,155 & 0,218 & 0,085 \\
\hline ED4 & 0,269 & 0,447 & 0,704 & 0,130 & 0,043 & 0,271 & 0,211 & 0,240 & 0,164 & 0,069 \\
\hline EF1 & 0,190 & 0,222 & 0,235 & 0,956 & 0,145 & 0,254 & 0,026 & 0,192 & 0,080 & 0,164 \\
\hline EF2 & 0,052 & 0,003 & 0,149 & 0,260 & 0,165 & 0,186 & $-0,068$ & 0,310 & 0,280 & 0,341 \\
\hline EF3 & $-0,048$ & 0,084 & 0,120 & $-0,244$ & 0,173 & 0,105 & $-0,103$ & 0,260 & 0,180 & 0,221 \\
\hline F1 & 0,032 & 0,014 & 0,015 & 0,115 & 0,150 & 0,142 & $-0,046$ & 0,309 & 0,197 & 0,219 \\
\hline F2 & 0,113 & $-0,058$ & 0,105 & 0,133 & 0,529 & 0,333 & $-0,020$ & 0,282 & 0,193 & 0,198 \\
\hline F3 & 0,079 & 0,154 & 0,114 & 0,093 & 0,368 & 0,174 & $-0,067$ & 0,283 & 0,196 & 0,238 \\
\hline F4 & 0,194 & 0,208 & 0,102 & 0,065 & 0,907 & 0,336 & 0,153 & 0,254 & 0,263 & 0,167 \\
\hline 12 & 0,198 & 0,090 & 0,074 & 0,055 & 0,117 & 0,146 & 0,766 & 0,029 & 0,111 & 0,107 \\
\hline INT2 & 0,593 & 0,333 & 0,425 & 0,187 & 0,308 & 0,822 & 0,220 & 0,362 & 0,175 & 0,155 \\
\hline INT3 & 0,419 & 0,170 & 0,297 & 0,176 & 0,406 & 0,822 & 0,182 & 0,518 & 0,349 & 0,370 \\
\hline INTE1 & 0,309 & 0,281 & 0,174 & 0,161 & 0,279 & 0,698 & 0,168 & 0,445 & 0,386 & 0,374 \\
\hline IS3 & 0,350 & 0,179 & 0,248 & 0,037 & 0,107 & 0,254 & 0,932 & 0,137 & 0,147 & 0,142 \\
\hline $\mathrm{MH} 1$ & 0,348 & 0,271 & 0,313 & 0,130 & 0,227 & 0,451 & 0,070 & 0,905 & 0,410 & 0,396 \\
\hline $\mathrm{MH} 2$ & 0,332 & 0,225 & 0,266 & 0,161 & 0,295 & 0,501 & 0,059 & 0,912 & 0,406 & 0,444 \\
\hline $\mathrm{MH} 3$ & 0,384 & 0,229 & 0,235 & 0,057 & 0,256 & 0,483 & 0,160 & 0,830 & 0,277 & 0,183 \\
\hline PRE1 & 0,068 & 0,216 & 0,163 & 0,048 & 0,279 & 0,292 & 0,103 & 0,347 & 0,851 & 0,329 \\
\hline PRE2 & 0,185 & 0,242 & 0,274 & 0,037 & 0,262 & 0,343 & 0,161 & 0,396 & 0,973 & 0,342 \\
\hline PRE3 & 0,030 & 0,460 & 0,224 & 0,052 & 0,129 & 0,218 & 0,083 & 0,257 & 0,561 & 0,152 \\
\hline TC4 & 0,135 & 0,082 & 0,076 & 0,094 & 0,199 & 0,312 & 0,161 & 0,307 & 0,309 & 0,842 \\
\hline TEC2 & 0,146 & 0,078 & 0,057 & 0,105 & 0,142 & 0,281 & 0,095 & 0,340 & 0,296 & 0,867 \\
\hline
\end{tabular}

Fonte: dadosda pesquisa

Tabela 7 - Fornell-Larcker

\begin{tabular}{|c|c|c|c|c|c|c|c|c|c|c|}
\hline \multicolumn{11}{|c|}{ Fornell-Larcker } \\
\hline Indicador & CEN & $\mathrm{CT}$ & ED & EF & $\mathbf{F}$ & INT & IS & MH & PRE & TEC \\
\hline CEN & 0,833 & & & & & & & & & \\
\hline CT & 0,337 & 0,807 & & & & & & & & \\
\hline ED & 0,444 & 0,425 & 0,772 & & & & & & & \\
\hline EF & 0,199 & 0,183 & 0,198 & & & & & & & \\
\hline $\mathrm{F}$ & 0,214 & 0,151 & 0,137 & 0,098 & & & & & & \\
\hline INT & 0,594 & 0,340 & 0,411 & 0,224 & 0,419 & 0,783 & & & & \\
\hline IS & 0,338 & 0,168 & 0,212 & 0,050 & 0,126 & 0,247 & 0,853 & & & \\
\hline $\mathrm{MH}$ & 0,405 & 0,274 & 0,307 & 0,129 & 0,294 & 0,543 & 0,112 & 0,883 & & \\
\hline PRE & 0,156 & 0,287 & 0,269 & 0,045 & 0,280 & 0,353 & 0,154 & 0,410 & 0,814 & \\
\hline TEC & 0,165 & 0,094 & 0,077 & 0,117 & 0,198 & 0,346 & 0,148 & 0,379 & 0,354 & 0,854 \\
\hline
\end{tabular}

Fonte: dados da pesquisa

A verificação pelo critério HTMT é semelhante aos das cargas cruzadas e Fornell-Larcker, visando determinar se o construto é único (HENSELER et al., 2009). Os valores de HTMT entre as relações dos construtos devem ser menores que 0,900 . 
Tabela 8 - Heterotrait-Monotrait Ratio (HTMT)

\begin{tabular}{|c|c|c|c|c|c|c|c|c|}
\hline \multicolumn{9}{|c|}{ HTMT $<0,900$} \\
\hline Indicador & CEN & CT & ED & INT & IS & MH & PRE & TEC \\
\hline \multicolumn{9}{|l|}{ CEN } \\
\hline CT & 0,389 & & & & & & & \\
\hline ED & 0,532 & 0,627 & & & & & & \\
\hline INT & 0,695 & 0,438 & 0,531 & & & & & \\
\hline IS & 0,427 & 0,229 & 0,293 & 0,339 & & & & \\
\hline $\mathrm{MH}$ & 0,458 & 0,324 & 0,384 & 0,717 & 0,125 & & & \\
\hline PRE & 0,141 & 0,472 & 0,367 & 0,499 & 0,189 & 0,491 & & \\
\hline TEC & 0,226 & 0,134 & 0,130 & 0,570 & 0,228 & 0,524 & 0,469 & \\
\hline
\end{tabular}

Fonte: dados da pesquisa.

Modelo de Mensuração - Formativo

A verificação da colinearidade entre indicadores formativos é necessária por altos níveis de colinearidade pode impactar na mensuração dos pesos e sua significância estatística (HAIR et al., 2014). $O$ valor de VIF do item deve ser maior que 0,2 e menor que 5, o valor de VIF do item EF1 foi 1,089; EF2 foi 1,205; EF3 foi 1,111; F1 foi 1,344; F2 foi 1,295; F3 foi 1,246 e F4 foi 1,214. Assim, foi constatado que todos os valores VIF são adequados.

Para a análise da significância e relevância dos construtos formativos no modelo de mensuração, são analisados os pesos externos e cargas externas. Segundo Hair et al. (2014), os valores dos pesos externos podem ser comparados entre si para a verificação da contribuição relativa de cada indicador para o construto, o que é denominado importância relativa. Os valores estimados de cargas externas indicam a importância absoluta dos indicadores para os construtos (HAIR et al., 2014). Somente se um indicador apresentar ambos, peso externo e carga externa, baixos ou não significativos é que deve ser excluído.

A tabela 9 mostra que apenas dois indicadores dos pesos externos possuem estatística T significantes, EF1 a $5 \%$ e F4 a 1\%, enquanto nas cargas externas, três indicadores possuem estatística T significante, EF1 é significante a $5 \%$, F2 é significante a $5 \%$ e F4 é significante a $1 \%$.

Tabela 9 - Pesos Externos e Cargas Externas

\begin{tabular}{|c|c|c|c|c|c|}
\hline \multirow{3}{*}{ Indicadores } & \multirow{2}{*}{\multicolumn{2}{|c|}{ Pesos Externos }} & \multicolumn{3}{|c|}{ Cargas Externas } \\
\hline & & & \multicolumn{2}{|c|}{$\begin{array}{l}\text { Modelo Estrutural } \\
\text { (Bootstrapping) }\end{array}$} & \multirow{2}{*}{$\begin{array}{c}\text { Modelo de Mensuração } \\
\text { (PLS ALG) } \\
\text { Carga }\end{array}$} \\
\hline & Estatística T & P Valor & Estatística T & P Valor & \\
\hline EF1 -> EF & 2,207 & 0,028 & 2,421 & 0,016 & 0,956 \\
\hline EF2 -> EF & 0,265 & 0,791 & 0,946 & 0,345 & 0,260 \\
\hline EF3 -> EF & 0,774 & 0,439 & 0,643 & 0,521 & $-0,244$ \\
\hline$F 1->F$ & 0,681 & 0,496 & 0,558 & 0,577 & 0,150 \\
\hline$F 2->F$ & 1,526 & 0,127 & 2,016 & 0,044 & 0,529 \\
\hline F3 -> F & 0,125 & 0,901 & 1,350 & 0,177 & 0,368 \\
\hline $\mathrm{F} 4->\mathrm{F}$ & 2,800 & 0,005 & 3,913 & 0,000 & 0,907 \\
\hline
\end{tabular}

Fonte: dados da pesquisa 


\section{Modelo Estrutural}

Para a análise do teste do modelo estrutural proposto pelo estudo, foram usados os coeficientes de caminho, os coeficientes de determinação e o SRMR. O modelo foi testado usando o software Smart PLS e o resultado é apresentado na Figura 2.

\section{Figura 2 - Modelo Estrutural}

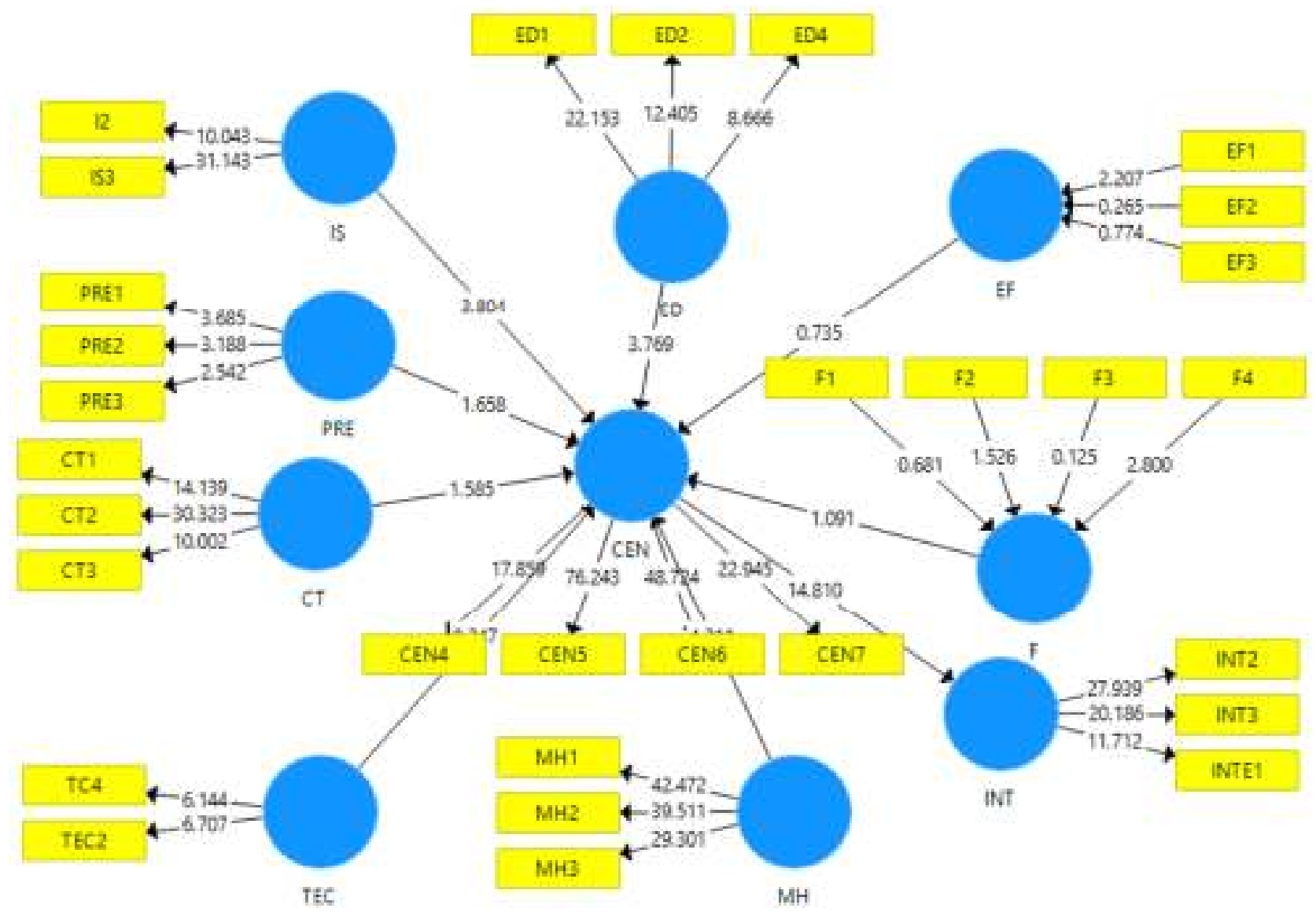

Fonte: dados da pesquisa

Os coeficientes de caminho representam as relações hipotéticas entre os construtos. Para identificar se um coeficiente é significativo foi usado o teste $T$. Os valores do teste $T$ devem ser superiores ao valor crítico, que é 2,570 para o nível de significância de 1\%, 1,960 para o nível de significância de 5\% e 1,570 para o nível de significância de 10\%. (HAIR et al., 2014). Como pode ser visto na tabela 10, três hipóteses são insignificantes, quatro hipóteses significantes a 1\% e duas hipóteses são significantes a 10\%. 
Tabela 10 - Coeficientes de Caminho

\begin{tabular}{|l|c|c|c|c|}
\hline Hipóteses & Estatística T & P Valor & Significância & Resultado \\
\hline CEN -> INT & 14,810 & 0,000 & $1 \%$ & Suportada \\
\hline CT -> CEN & 1,585 & 0,113 & $10 \%$ & Suportada \\
\hline ED -> CEN & 3,769 & 0,000 & $1 \%$ & Suportada \\
\hline EF -> CEN & 0,735 & 0,463 & Não Significante & Não Suportada \\
\hline F -> CEN & 1,091 & 0,275 & Não Significante & Não Suportada \\
\hline IS -> CEN & 3,804 & 0,000 & $1 \%$ & Suportada \\
\hline MH -> CEN & 4,211 & 0,000 & $1 \%$ & Suportada \\
\hline PRE -> CEN & 1,658 & 0,098 & $10 \%$ & Suportada \\
\hline TEC -> CEN & 0,247 & 0,805 & Não Significante & Não Suportada \\
\hline
\end{tabular}

Fonte: Saída do Software SmartPLS

O coeficiente de determinação é a medida do poder de previsão do modelo e o valor de $R^{2}$ varia entre 0 e 1 , sendo os valores mais próximos de 1 indicativos de maior poder de previsão. Os coeficientes de determinação devem ser avaliados pelos parâmetros de valores de 0,190, 0,330 e 0,670, sendo respectivamente, fracos, moderados e substanciais (HENSELER et al., 2009; HAIR et al., 2014). O R² de CEN é 0,364 e o $R^{2}$ ajustado é 0,338 e, para INT o $R^{2}$ é 0,353 e o $R^{2}$ ajustado é 0,350 . Todos os coeficientes de determinação para os dois construtos são considerados moderados.

O Standardized Root Mean Square Residual (SRMR), ou raiz quadrada média residual padronizada é definida como a diferença entre a correlação observada e a correlação prevista. Um valor até 0,100 (HU; BENTLER, 1998) é considerado bom. Nesta pesquisa o SRMR observado é 0,098 e o SRMR estimado é 0,112 .

\section{CONCLUSÃO}

A tecnologia streaming alterou a forma de consumir o entretenimento audiovisual. Procurando ampliar o entendimento desse processo, essa pesquisa tem por objetivo entender quais são os fatores de desempenho das plataformas de streaming que influenciam no consumo de entretenimento e na intenção de uso destas plataformas. O modelo UTAUT 2 e a pesquisa exploratória indicaram os fatores envolvidos no consumo de vídeos streaming, os quais foram testados como preditores da intenção de uso das plataformas.

Conclui-se da análise dos resultados que a tecnologia desviou o consumo de entretenimento audiovisual das redes de televisão para as plataformas streaming. Os fatores determinantes desse movimento foram a expectativas de desempenho, a influência social, a motivação hedônica, o preço e o custo de troca.

O consumidor viu nessas plataformas um conteúdo vasto e diversificado que aumentou suas chances de encontrar o programa que deseja, sendo um serviço indispensável ao seu entretenimento. Além disso, para se sentirem incluídos no seu grupo social, eles se sujeitam à influência de amigos e grupos de referência que estimulam a aquisição do serviço. Assim, uma vez que essa forma de entretenimento é agradável e divertida a um preço justo, o consumidor percebe, no caso específico da Netflix, que tem um custo deixar essa plataforma em troca de outra, não valendo a pena buscar uma plataforma alternativa. Portanto, o 
consumidor que utiliza serviços streaming pretende continuar comprando esses serviços no futuro e usá-lo frequentemente no seu dia-a-dia.

Curiosamente os aspectos tecnológicos do serviço, como a criação de múltiplos perfis e estabelecimento de preferências, a facilidade do seu uso, o qual não exige muitos conhecimentos e recursos, sendo acessivel a partir de qualquer dispositivo conectado à Internet, o que significa baixa expectativa de esforço em seu manuseio, não foram determinantes do consumo das plataformas streaming.

Uma possível explicação para esse resultado é que o consumidor talvez já esteja familiarizado com a tecnologia, portanto, ela em si não é um motivo para a adoção de novos hábitos do consumo de entretenimento. No entanto, quando ela viabiliza um entretenimento inovador, pautado no desempenho superior, na aprovação social e no baixo preço então se estabelece uma nova praxe de diversão com intenção continuada de uso no futuro.

A amostra foi formada predominantemente por jovens e adultos de 18 a 35. Talvez seja por esse motivo que esses fatores tenham sido determinantes da adoção de plataformas streaming. Muitas pessoas nesse grupo ainda moram com os pais, os quais são de fato os contratantes do serviço. Possivelmente, esse não seria o resultado em se tratando do público maior de 35 anos. Nessa perspectiva, variáveis como facilidade de contratação, suporte técnico para o enfrentamento de problemas e facilidade de conexão e navegação na plataforma poderiam ser mais relevantes na adoção dessa tecnologia. Portanto, fica como sugestão para estudos posteriores que se investigue o consumo dessa nova forma de entretenimento tendo a idade por variável moderadora.

\section{REFERÊNCIAS}

ALAZZAM, M. B.; BASARI, S. H.; SIBGHATULLAH, A. S.; RAMLI, M. R.; JABER, M. M.; NAIM, M. H. Pilot study of ehrs acceptance in jordan hospitals by utaut2. Journal of Theoretical and Applied Information Technology, v. 85, n. 3, 2016.

ALVES, J. N.; PEREIRA, B. A. D. Análise da Teoria Unificada de Aceitação e Uso de Tecnologia em uma Grande Rede Interorganizacional de Cooperação. VIII Encontro de Estudos Organizacionais da ANPAD, 2014.

BARBOZA, E. F. U.; SILVA, A. C. A. Informação sob demanda: novas plataformas para uma comunicação digital personalizada. Revista Comunicação, Cultura e Sociedade, v. 1, n. 2, 2014.

BONN, M. A.; KIM, W. G.; KANG, S.; CHO, M. Purchasing Wine Online: The Effects of Social Influence, Perceived Usefulness, Perceived Ease of Use, and Wine Involvement. Journal of Hospitality Marketing \& Management, p. 1-29, 2015.

CAMARGO, C. História da Televisão, 2009. Disponível em:< http://www.tecmundo.com.br/projetor/2397-historia-datelevisao.htm/>. Acesso em: 12 de out. 2016.

CAPANEMA, L.; FRANÇA, R. O. A televisão no ciberespaço: reformulações da televisão na internet e na TV digital. Revista GEMInIS, n. 1, Ano 4, p. 20-36, 2013.

COUTINHO, M. Saiba mais sobre streaming, a tecnologia que se popularizou na web 2.0, 2014. Disponível em:< http://glo.bo/18u3MFg />. Acesso em: 01 de out. 2016.

DAVIS, F. D. Perceived usefulness, perceived ease of use, and user acceptance of information technology. MIS quarterly, V. 13, n. 3, p. 319-340, 1989.

FARIA, L. H. L.; GIULIANI, A. C.; PIZZINATTO, N. K.; PIZZINATTO, A. K. Applicability of Unified Theory of Acceptance and Use of Technology Extended to the Consumer Use Context (UTAUT2) in Brazil: An Evaluation of the Model Using a Sample of Internet Users on Smartphones. Revista de Administração da UFSM, v. 7, n. 2, 2014.

GIL, A. C. Métodos e técnicas de pesquisa social. 6. ed. São Paulo: Atlas, 2008.

GOSLING, M. Estratégias de Relacionamento no Setor Bancário Brasileiro: Um Estudo Empírico. 2001. 315 f Dissertação (Mestrado em Administração) - Centro de Pós Graduação e Pesquisa em Administração, Universidade Federal de Minas Gerais, Belo Horizonte, 2001.

GUTMANN, J. F.; CERQUEIRA, Í. Novos e velhos modos de ver TV: O que disputam os internautas sobre o consumo de série televisiva? Verso e Reverso, v. 30, n. 74, p. 110-120, 2016. 
HAIR, J.; ANDERSON, R. E.; TATHEM, R. L. \& BLACK, W. C. Análise Multivariada de Dados. Porto Alegre: Bookman. 2005.

HAIR, J.; HULT, G. T. M.; RINGLE, C. M.; SARSTEDT, M. A Primer on Partial Least Squares Structural Equation Modeling (PLS-SEM). Los Angeles: Sage Publications, 2014.

HENSELER, J.; RINGLE, C. M.; SINKOVICS, R. R. The use of partial least squares path modeling in international marketing. Advances in International Marketing (AIM), v. 20, p. 277-320, 2009.

HERRMANN, L. A convergência midiática e as mudanças comportamentais no consumo do mercado de nicho: Netflix e a "desmaterialização" dos produtos. Animus Revista Interamericana de Comunicação Midiática, v. 11, n. $22,2012$.

HU, L. T.; BENTLER, P. M. Fit indices in covariance structure modeling: sensitivity to underparameterized model misspecification. Psychological Methods, v. 3, n. 4, p. 424-453, 1998.

HUANG, C. Y.; KAO, Y. S. UTAUT2 based predictions of factors influencing the technology acceptance of phablets by DNP. Mathematical Problems in Engineering, v. 2015, 2015.

INDRAWATI; HARYOTO, K. S. The Use of Modified Theory of Acceptance and Use of Technology 2 to predict prospective users' intention in adopting TV streaming. In: Proceedings of the 5th International Conference on Computing and Informatics. ICOCI 11-13 August 2015, Istanbul, Turkey.

KIT, A. K. L. UTAUT2 influencing the behavioural intention to adopt mobile applications. 2014. Tese (Doutorado). University Tunku Abdul Rahman. 2014.

MALHOTRA, N. K. Pesquisa de Marketing: Uma Orientação Aplicada. 5.ed. Porto Alegre: Bookman, 2004.

MATHUR, S. K.; DHULLA, T. V. Factors Influencing Professionals' Decision for Cloud Computing Adoption. International Journal of Research in Advent Technology, v. 2, n. 4, 2014.

MORAES, G. H. S. M.; CAPPELLOZZA, A.; FLORES, E. S.; ARRAIS, E. F. Curtir mais, Pagar menos-Adoção às Compras Coletivas pelo Consumidor Final. Revista Gestão \& Tecnologia, v. 14, n. 2, p. 79-100, 2015.

NUNES, L. F. da M. Consumo de música: os social media e os serviços de streaming. 2015. Dissertação (Mestrado) Universidade de Lisboa. Instituto Superior de Economia e Gestão. 2015.

ROSSINI, M. S.; RENNER, A. G. Nova cultura visual? Netflix e a mudança no processo de produção, distribuição e consumo do audiovisual. Congresso Brasileiro de Ciências da Comunicação (Rio de Janeiro, RJ). Anais. Rio de Janeiro:Intercom, 2015.

SANTOS, T. C. Web streaming, suas tendências: e o caso ParatyTv. 2014. 98 f. Dissertação (Mestrado em Mídias Digitais) - Pontifícia Universidade Católica de São Paulo, São Paulo, 2014.

THOMPSON, R. L.; HIGGINS, C. A.; HOWELL, J. M. Personal computing: toward a conceptual model of utilization. MIS quarterly, v. 15, n. 1, p. 125-143, 1991.

VENKATESH, V.; MORRIS, M.; DAVIS, G.; DAVIS, F. User Acceptance of Information Technology: Toward a Unified View. MIS Quarterly, v. 27, n. 3, p. 425-478, 2003.

VENKATESH, V.; THONG, J.; XU, X. Consumer acceptance and use of information technology: extending the unified theory of acceptance and use of technology. MIS Quarterly, v. 36, n. 1, p. 157-178, 2012.

VERA, L. A. R. Fatores Motivadores de Compras Coletivas na Internet: Um Estudo Com Base no Modelo de Aceitação e Uso de Tecnologia 2. Dissertação (Mestrado em Administração), Universidade Federal da Bahia, 2014. 